Review

\title{
Do Adolescents Prefer Electronic Books to Paper Books?
}

\author{
Margaret K. Merga \\ Murdoch University, South Street, Murdoch WA 6150, Australia; E-Mail: m.merga@murdoch.edu.au; \\ Tel.: +61-8-9360-2378
}

Academic Editor: Craig Smith

Received: 5 August 2015 / Accepted: 6 November 2015 / Published: 11 November 2015

\begin{abstract}
While electronic books offer a range of benefits and may be supposed to be more appealing to young people than paper books, this assumption is often treated as fact by educational researchers. Understanding adolescents' true current preferences is essential, as incorrect assumptions can lead to decisions which restrict adolescent access to their preferred book mode. The belief that adolescents prefer electronic books to paper books has already led to some school libraries being expunged of paper books. As adolescents show a higher level of aliteracy than younger children, and regular reading offers a broad range of benefits for young people, it is imperative that school's decisions around providing access to books are responsive to adolescent students' genuine preferences. This paper analyses the current and relevant academic research around adolescent preferences for book modes, finding that, at present, the contention that adolescents prefer electronic books is not supported by the available research. In addition, there are a number of issues identified that make analyzing the findings in this area problematic. Future studies in this area are needed before an adolescent preference for electronic books can be unequivocally substantiated.
\end{abstract}

Keywords: eBook; eReader; paper book; reading; adolescents

\section{Introduction}

The advent of the eReader has led to exciting new possibilities for reading books. While eBooks have been in existence since 1971 [1], the 2007 entry of Amazon into the device market, coupled with its strong distribution focus, has led to increased interest in eReaders [2]. However, predictions that the surge in interest in eBooks would lead to paper books becoming obsolete have not come to fruition, 
as the rise in eBook purchases and corresponding fall in print book purchases has been arrested, with eBook sales stabilizing at around $10 \%$ to $20 \%$ of all book sales [3]. The eBook is read on an eReader, with reading eBooks either the primary purpose (e.g., Kindle and Kobo eReaders) or part of the multiple purposes offered by the device (e.g., reading a book using a Kobo application on an iPad renders the iPad an eReader). An eBook is any electronic file (e.g., mobi or epub) containing text, which, if in paper form, would be recognized as a book. As such, this definition encompasses both fiction and non-fiction, and it excludes non-book text types such as journal articles.

The eReader offers numerous benefits, most notably portability, offering the capacity to carry a virtual library of books in one slim device, and as such, research suggests that the eBook is greatly preferred to the printed book for the purposes of reading a book while traveling [4]. It is generally quick and easy to purchase or borrow new books using an eReader, and eReaders offer additional features such as of built-in dictionaries and capacities such as hyperlinking. The extra features of eBooks may offer significant benefits for readers who struggle with font sizes in paper books, with this capacity rated highly among children with learning disabilities, along with text to speech features, and the aforementioned dictionary feature [5]. The eBook offers a similar experience to reading a paper book, as well as "stand-alone capability (no computer required), fast downloading, thin cases, large storage capacity, and access by either wired or wireless internet" [6]. It also offers scope to read in a public environment simultaneously shielding the text choice from view, which can be felt to be advantageous where reading preference may not be socially acceptable or desirable [2,7].

The eBook lacks some of the advantages of the paper book. Whereas a paper book is owned by its purchaser, leaving them free to share the book without constraint, the eBook is licensed, leading to ongoing contention over the use of digital rights management (DRM) technologies to prevent the unauthorised sharing of eBooks [2]. These DRM mechanisms can be frustrating for users, in that they add to the complexity of locating and reading eBooks, particularly for academic users [8]. Annotations made in print books may offer greater comparative privacy and permanence. For example, the annotations of eBook readers can be lost in instances of eBook withdrawal by sellers, which is permissible under existing licensing agreements, and was notably exercised in 2009 when Amazon deleted George Orwell's 1984 from its customers Kindles following the revelation that they did not have adequate electronic distribution rights [2]. While the current range of eBooks may be inferior, with only $20 \%$ of US adult eBook users always able to access books in their preferred format [4], it can be anticipated that this availability is likely to improve over time. The inability to write directly on an eBook can pose an issue, as while most eReaders "give readers the opportunity to highlight, create notes, look up/define words, and bookmark, creating, organizing, and managing these notes may require different literacy and study skills compared to the skill set needed to read a traditional text" [9], and these tools vary between devices. While the aforementioned benefit of a built-in dictionary may improve comprehension, it can also disrupt comprehension by leading to breaks in reading fluency [9], and impede student development of word decoding strategies, such as reading around the word to determine its meaning, as they are no longer necessary.

The fact that eBooks do not need to be printed is represented as an advantage, leading to the suggestion that they are an environmentally friendly alternative [1]; however, this claim has been contested, as it is highly dependent on volume of eReader use, as "the more eBooks read on a single eReader, the greater the potential offset vs. paper books" [10]. In addition, while eBooks may have the 
advantage of easy initial access, print books may provide easier ongoing access, as they are not dependent on device recharging, nor are they required to meet the requisites of a DRM agreement, which expire or are revoked. Some eBook platforms are dependent on an ongoing internet connection if licensing excludes downloading, such as is the often the case when eBooks are being read through academic libraries [8]. In addition, eBook files may lack immediate compatibility between devices and require conversion to be read between devices. For example, at this stage, eBooks "purchased" through the iTunes store on an iPad or other Apple product cannot be read on a Kobo reader.

There may also be additional health implications to consider in nighttime eReader use. Research suggests that artificial light exposure resulting from using eReaders at night may interfere with users' ability to sleep, ultimately leading to adverse impacts on health [11], though not all eReaders use light-emitting technology, with some reflecting light instead, such as E Ink [12]. Reading digital texts has been associated with optical discomfort, though the degree varies depending on the device used, and that eReaders may actually be "potentially superior to printed paper in terms of optics", as the experience can be customized, with font increases and other adjustments, as required [3].

\section{Why Does Adolescent Preference Matter?}

In addition to the benefits previously listed, there are a number of reasons that educators may wish that adolescents show a preference for eBooks, and often this desire evolves into a strongly held belief, the empirical basis of which is the central point of contention addressed in this paper. Even raising it as a point of contention is controversial in the face of the strong push in education to be modern and embrace the "new", to maintain the relevance of the learning experiences that we provide, and to equip our students to be proficient communicators in an environment where digital literacy skills are important, highly valued, and increasingly measured for the purposes of comparison, by mechanisms such as the 2009 Programme for International Student Assessment (PISA) Digital Reading Literacy Assessment [13] and the 2013 International Computer and Information Literacy Study [14].

Adolescent preference for eBooks or paper books needs to be understood, and researched without overt bias, as adolescents have much to lose if characterized as a homogenous mass of digital natives before this characterization is valid. The prevailing belief that all adolescents will automatically prefer eBooks to paper books as popularized by Prensky [15] has been used to justify sweeping changes in the provision of reading materials, with some school and community libraries in the US and Australia removing paper books entirely and replacing them with eBooks [7]. This change is occurring despite the current lack of empirical evidence to support the contention that all young people fit the digital native characterization of broad technological confidence, preference and proficiency [16]. While research suggests that adolescents' use of technology is high, with a recent report indicating that $92 \%$ of US teenagers access the internet on a daily basis [17], skill and confidence levels vary, and it cannot be assumed that just because an individual makes frequent use of the internet, they will necessarily prefer to read eBooks rather than paper books. In addition, factors such as socioeconomic background may also potentially play a significant role in variation in technological proficiency in the so-called "Net Generation" [18].

Adolescents are already at risk of aliteracy, the state in which those with the skill to read choose not to exercise it, with many adolescents reluctant to spend their recreation time reading books [19,20], 
and a decline in reading for pleasure has been noted across the majority of countries participating in Organisation for Economic Co-operation and Development (OECD) research [21]. Regular recreational reading is a highly beneficial practice, as it is associated with significant gains across a range of literacy outcomes [22-24]. Regular reading may also offer protection against cognitive decline [25,26] and foster empathy [27-29].

If books are no longer available to adolescents in the form that they prefer or find most accessible, this could lead to a further drop in their readiness to engage in reading. Reluctance to read may exclude adolescents from experiencing the aforementioned literacy benefits. If a homogenous preference for one form of the book over the other is not yet established, wherever possible, access to both paper books and their electronic counterparts should be made available where resourcing limitations permit. There are also equity implications in withdrawing access to paper books, with research informed primarily by young adult and adult respondents suggesting that in addition to age, education and income can influence willingness to engage in the eReading experience [30,31], and that gender may also be a factor [32]. While schools' promotion of eBooks offers great potential for supporting a mechanism for reading at home, and access to books in the home has been associated with greater reading frequency, positive attitudes toward reading, and literacy benefit, it cannot be assumed that eReaders and eBooks necessarily represent a holistic, multi-contextual solution; research suggests that keen readers with access to eReaders still prefer to read paper books [7]; therefore, it is premature to suggest that eBook readers will effectively mitigate the effect of limited access to books in the home [33]. In addition, while US research suggests that young people's exposure to eBooks and access to eReading technology is increasing over time, most adolescents still believe that they will "always want to read books printed on paper even though there are eBooks available" [34].

\section{Review}

The aim of this paper was to conduct a review of the recent academic research exploring the research question: Do adolescents prefer electronic books to paper books? As the number of studies in this area was found to be very low, it was necessary to create a process to conduct this review that included qualitative, quantitative and mixed-method studies. The method devised for this review was primarily informed by Khan's et al.'s five step reviewing process, which involves framing focus questions, identifying relevant work, "assessing the quality of studies", "summarizing the evidence", and "interpreting the findings" [35].

\subsection{Methods}

\subsubsection{Definitions}

While the definition for age qualifying as adolescence varies greatly, for the purposes of this study the World Health Organization's (WHO) delimitation of adolescence has been adopted, as being between the ages of 10 and 19 [36]. As such, students from middle school to the early years of post-secondary education are encompassed within this range. 


\subsubsection{Search Strategy}

Currency and relevance were placed as paramount in devising the search strategy. The key search terms were devised from perusal of frequently occurring keywords in this field, taking care to avoid being too narrow in their delimitation.

Common names for electronic books were deemed to be electronic books, ebooks, e-books, and digital readers. Common names for adolescents included adolescent, teenager, and in some cases, student. A total of 12 key word searches were undertaken as follows: adolescent electronic book reading; adolescent ebook reading; adolescent e-book reading; adolescent digital reader; teenager electronic book reading; teenager ebook reading; teenager e-book reading; teenager digital reader; student electronic book reading; student ebook reading; student e-book reading; student digital reader.

These 12 search term groups were entered from 17 June 2015 to 30 June 2015 into Google Scholar. While Google Scholar was used as the search engine, items were not limited to those available through Google Scholar. The institutional library database was used to access articles that were cited in Google Scholar but were not accessible in full through Google Scholar.

The date range was customized to span 2010-2015 to ensure currency of results, to prevent a negative skew to findings derived from usability issues of early incarnations of eReading devices. Only peer-reviewed journal articles were included. Research reports, theses, books, conference papers and other texts were excluded. Results from the first 10 pages of responses for each search, as ordered by relevance, were included, as the search terms were so broad, relevance quickly began to decline in the quality of results. While both quantitative and qualitative studies were included for review, literature reviews were excluded.

There were a number of other exclusion criteria applied to ensure the currency and relevance of the findings. Studies that did not provide insight into the comparative experience, focusing only on the benefits of one mode or the other, were excluded, as they did not offer anything to support the research question. While results from all geographic locations were deemed relevant, results were rejected where age parameters as defined by the accepted working definition from WHO were not compliant, even if the number of respondents outside the desired range was small.

Key reasons for exclusion of research items included the lack of specification of respondents' ages, lack of comparison between attitudes toward reading eBooks and paper books, and the presence of participants who fell outside the age range.

\section{Results and Discussion}

A total of four compliant studies were sourced. Findings from these studies often extended beyond the research question, but those beyond its scope are not reported in the summative Table 1. 
Table 1. Tabulated review of literature.

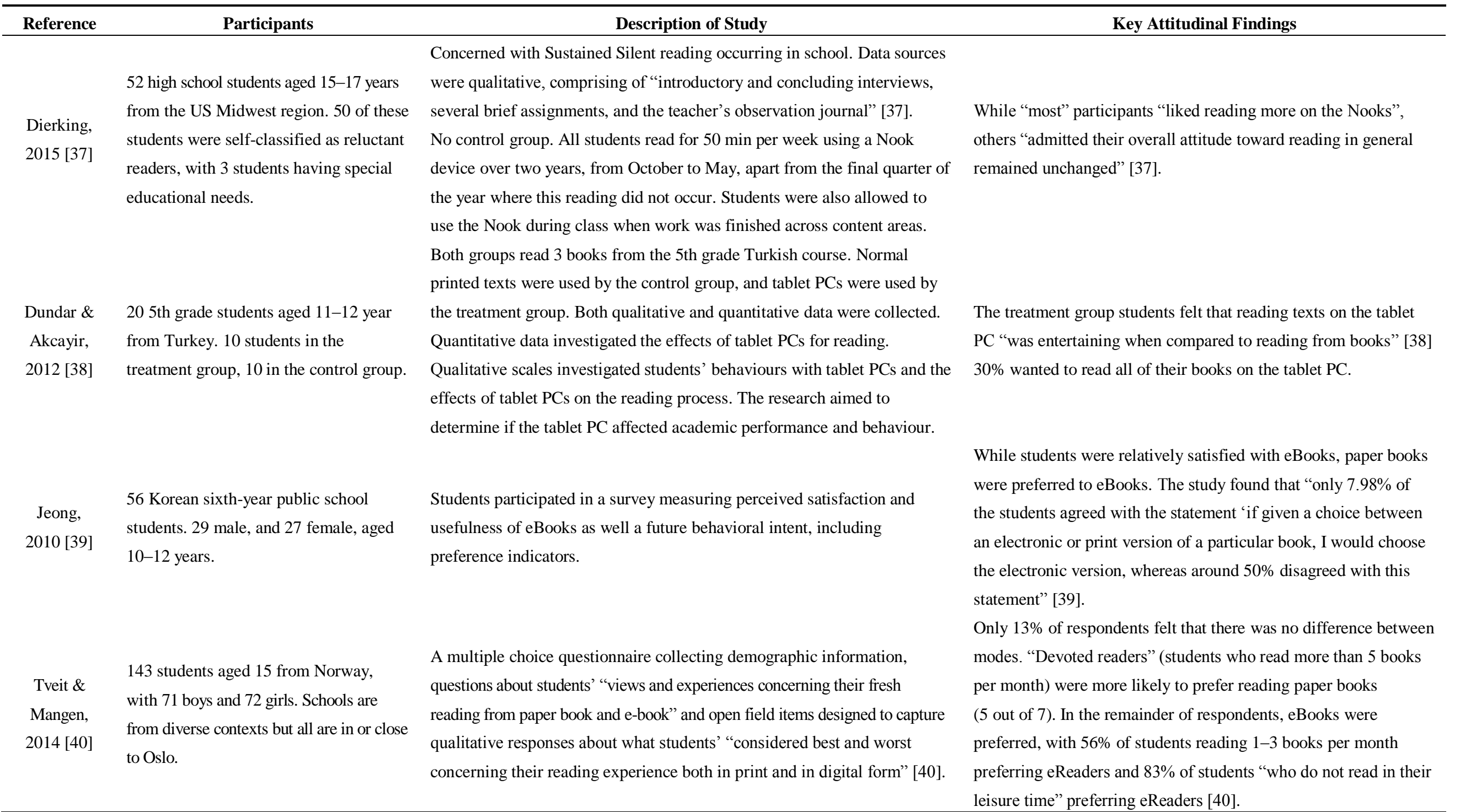




\section{Discussion}

The above findings would suggest that the body of research is not sufficiently compelling to support an unequivocal assertion that at this stage, adolescents prefer electronic books to paper books. In addition to the limited quantity of recent academic research studies with adolescents that address this research question $(n=4)$ that meet the currency and relevance requisites as previously outlined, a number of additional issues arise, the most obvious being the lack of consensus between the studies, with three of the studies indicating a positive finding in favor of eBooks, and one of the studies indicating a positive finding toward paper books. The findings in the studies were also derived from small sample sizes, ranging from just 20 to maximum of 143.

The vast methodological and contextual difference between the studies makes comparison problematic. Extrapolating findings across reading purposes is questionable; reading for information may involve different cognitive processes and affective factors when compared to reading for pleasure, so a positive finding for one purpose does not necessarily mean the results would also have been positive if applied for another purpose. It is possible that "eBooks are more likely to appeal to students reading for information rather than for pleasure, where interactive links and options may provide further, welcome information" [7]. Dutch research focusing on an older demographic suggests that paper based texts may be "a superior medium for learning and digesting complicated and elaborate texts, whilst electronic screens are appreciated for quick information gathering, communication and navigation" [41], with a review of research suggesting that academic users typically search eBooks for small units of information, exhibiting "behaviour that can be summed up by the formula 'use rather than read"' [42]. Comparative research exploring adolescent preference across eBook and paper differences and reading purpose differences is indicated in order to increase understanding in this area. The difference in enjoyment of reading for pleasure or information, reading fiction or non-fiction, reading books or other text types also need to be explored, as some of the studies drew results from one reading experience, based on reading one text.

Qualitative studies pose difficulty in review. For example, Dierking [37] found that while most students preferred Nooks, some maintained their overall reluctant attitude toward reading. Clearly, "most" and "some" are relatively subjective terms, and while these insights are valuable in the source context, this method of research design and reposting does not lend itself to comparison of findings, such as to meet the requirements of this paper. Preferences in Dundar and Akcayir [38] were also derived from qualitative data from a very small sample size in the treatment group (10 students), thus the finding that $30 \%$ of 10 students wished to read solely on devices only constituted three people. Quantitative studies were also small in a number of cases. Jeong's [39] finding of a preference for paper book reading over eBook reading was generated from a sample of only 56. All of the studies were monocontextual and as such, no international studies were included. As such, the limitations of the particular context, compounded by the aforementioned small sample sizes, made it very difficult to compare the studies, and to draw cross-applicable conclusions from the findings.

One of the studies was almost excluded due to the school recruitment process employed. Tveit and Mangen [40] recruited one of its schools for participation in their study on the basis that the staff were favorably disposed toward technology, stating that "School H was chosen due to the staff's interest and engagement in digital teaching tools" and that "this school was recruited through 
The Norwegian Centre for Information and communications technology (ICT)in Education". It can be surmised that this form of convenience recruiting can have an impact on the students' attitudes that are being measured, and staff who are interested in, and engaged in the use of digital teaching tools may be more likely to influence students to view them favorably.

Similar bias was also found in the design of some studies that were excluded for other reasons. For example, in a US study of younger children's "involvement with and response to digital readers" [43] occurred in a site where their classroom teacher had actively positioned children in advance, to produce a favorable response: "Mrs. Miles, the classroom teacher, is an avid proponent of technology integration who encouraged her 17 second graders to read online texts, blog about their reading experiences, and engage in online literature discussions." [43]

It would appear that in some cases, the research appearing in peer-reviewed international literacy and education journals in this area may lack sufficient objectivity. The degree of enthusiastic advocacy from educators around eBook use, whatever the root causes, has led to issues with research design, with one of the key issues that impacts on the validity of the studies in this area being the partial and often vested interests present in those conducting the study.

The review also compared studies using different devices. For instance, while Dierking [37] used Nooks, Dundar and Akcayir [38] used tablet PCs. None of the studies compared preference across more than one device, and thus even within findings for a preference for eBooks, it is not known if this preference is specific to the eBook mode, or reflective of the particular device used. Research with graduate students suggests that user satisfaction can vary across device types [44]. The difference between the experience on sole-purpose readers, such as the Kindle or Kobo, as compared with the multiple purpose reader, such as an iPad with an eReading application, could also be considered. Reading on a sole purpose device allows reduced opportunities for distraction on the device, whereas those reading on a tablet such as an iPad may read and perform other tasks, such as checking status updates on social media and running internet searches, without having to move between devices. Even sole purpose readers "support both the immersive reading of a single text and the expansive skimming of multiple texts" [2] and, therefore, they offer greater opportunities for both choice and distraction.

\section{Conclusions}

Clearly more research needs to be conducted in this area before educators who are advocates of eBooks can validly claim that adolescents prefer eReaders. While advocates of eBooks or paper books can perform valuable research in this field, it is essential that the research design they implement be free of bias toward a preferred finding for their research to make a contribution to the field.

This paper calls for a large international study to be conducted in this area. It is suggested that the study address issues in previous research in this area by having the following key features:

- Include a quantitative component or be entirely quantitative in nature.

- Avoid subjectivity and anticipating results in design and reporting.

- Draw responses from a robust and ideally representative sample size.

- Distinguish between reading for pleasure and reading for information. 
- Utilize a sample recruitment process that avoids bias toward a positive finding in either direction, and acknowledges any limitations encountered when enacting the recruitment mechanism.

- Be multi-contextual, ideally drawing findings from multiple nations.

- Clearly outline the features of the device model selected, so that the impact of device on preference, when it relates to advantages and disadvantages of device features, can be better understood by subsequent researchers.

Until a number of studies that meet the above minimum criteria have been conducted, educators should refrain from assuming that adolescents prefer eBooks, as acting on this assumption can have implications for student access to the mode that they most enjoy, and subsequently have a detrimental impact on adolescent reading frequency.

\section{Conflicts of Interest}

The author declares no conflict of interest.

\section{References}

1. Sieche, S.; Krey, B.; Bastiaens, T. Investigating students' usage and acceptance of electronic books. J. Educ. Multimed. Hypermed. 2013, 22, 465-487.

2. MacFadyen, H. The reader's devices: The affordances of ebook readers. Dalhous. J. Interdiscip. Manag. 2011, 7, 2-15.

3. Tanner, M.J. Digital vs. Print: Reading Comprehension and the Future of the Book. SLIS Stud. Res. J. 2014, 4, 6.

4. Rainie, L.; Zickuhr, K.; Purcell, K.; Madden, K.; Brenner, J. The Rise of e-Reading. Pew Research Centre: Washington, DC, USA, 2012.

5. Camardese, A.; Peled, Y.; Kirkpatrick, M.; Teacher, S.G. Using E-Readers to Improve Reading for Students with Mild Disabilities. J. Am. Acad. Special Educ. Prof. 2012, Spring-Summer, 7-24.

6. Lai J.; Chang, C. User attitudes toward dedicated e-book readers for reading. Online Inf. Rev. 2011, 35, 558-580.

7. Merga, M.K. Are teenagers really keen digital readers?: Adolescent engagement in ebook reading and the relevance of paper books today. Engl. Aust. 2014, 49, 27-37.

8. Slater, R. Why aren't e-books gaining more ground in academic libraries? E-book use and perceptions: A review of published literature and research. J. Web Librariansh. 2010, 4, 305-331.

9. Schugar, J.T.; Schugar, H.; Penny, C. A nook or a book: Comparing college students' reading comprehension level, critical reading, and study skills. Int. J. Technol. Teach. Learn. 2011, 7, 174-192.

10. Allender, B. Weighing the Environmental Costs: Buy an eReader, or a Shelf of Books? 2012. Available online: https://theconversation.com/weighing-the-environmental-costs-buy-anereader-or-a-shelf-of-books-8331 (accessed on 5 May 2015).

11. Chang, A.M.; Aeschbach, D.; Duffy, J.F.; Czeisler, C.A. Evening use of light-emitting eReaders negatively affects sleep, circadian timing, and next-morning alertness. Proc. Natl. Acad. Sci. USA 2015, 112, 1232-1237. 
12. Halpern, S. The iPad revolution. The New York Review of Books: New York, NY, USA, 2011; 10. Available online: http://www.nybooks.com/articles/archives/2010/jun/10/ipad-revolution/ (accessed on 9 November 2015)

13. Thomson, S.; de Bortoli, L. Preparing Australian Students for the Digital World: Results from the PISA 2009 Digital Reading Literacy Assessment; Australian Council for Educational Research: Camberwell, Australia, 2012.

14. Frailon, J.; Schulz, W; Ainley, J. The International Computer and Information Literacy Study Assessment Framework; IEA: Amsterdam, the Netherlands, 2013.

15. Prensky, M. Digital natives, digital immigrants, part 1. Horizon 2001, 9, 2-6.

16. Bennett, S.; Maton, K.; Kervin, L. The "digital natives" debate: A critical review of the evidence. Br. J. Educ. Technol. 2008, 39, 775-786.

17. Lenhart, A.; Duggan, M.; Perrin, A.; Stepler, R.; Rainie, L.; Parker, K. Teens, Social Media \& Technology Overview 2015; Pew Research Centre: Washington, DC, USA, 2015.

18. Hargittai, E. Digital na(t)ives? Variation in internet skills and uses among members of the “net generation". Sociol. Inq. 2010, 80, 92-113.

19. Merga, M.K. Are Western Australian adolescents keen book readers? Aust. J. Lang. Lit. 2014, 37, 161-170.

20. Kelley, M.J.; Decker, E.O. The current state of motivation to read among middle school students. Read. Psychol. 2009, 30, 466-485.

21. Organisation for Economic Co-operation and Development (OECD). Education at a Glance; OECD: Washington, DC, USA, 2011.

22. Berns, G.S.; Blaine, K.; Prietula, M.J.; Pye, B.E. Short-and long-term effects of a novel on connectivity in the brain. Brain Connect. 2013, 3, 590-600.

23. Mol, S.E.; Bus, A.G. To read or not to read: A meta-analysis of print exposure from infancy to early adulthood. Psychol. Bull. 2011, 137, 267-296.

24. Stanovich, K.E. Matthew effects in reading: Some consequences of individual differences in the acquisition of literacy. Read. Res. Q. 1986, 21, 360-407.

25. Vermuri, P; Mormino, E.C. Cognitively stimulating activities to keep dementia at bay. Neurology 2013, 81, 308-309.

26. Wilson, R.S.; Boyle, P.A.; Yu, L.; Barnes, L.L.; Schneider, J.A.; Bennett, D.A. Life-span cognitive activity, neuropathologic burden, and cognitive aging. Neurology 2013, 81, 314-321.

27. Kidd, D.C.; Castano, E. Reading literary fiction improves theory of mind. Science 2013, 342, 377-380.

28. Mar, R.A.; Oatley, K. The function of fiction is the abstraction and simulation of social experience. Perspect. Psychol. Sci. 2008, 3, 173-192.

29. Mar, R.A.; Oatley, K.; Peterson, J.B. Exploring the link between reading fiction and empathy: Ruling out individual differences and examining outcomes. Communications 2009, 34, 407-428.

30. Jung, J.; Chan-Olmsted, S.; Park, B.; Kim, Y. Factors affecting e-book reader awareness, interest, and intention to use. New Media Soc. 2011, 14, 204-224.

31. Rainie, L.; Duggan, M. eBook Reading Jumps; Print Book Reading Declines; Pew Research Centre: Washington, DC, USA, 2012. 
32. Revelle, A.; Messner, K.; Shrimplin, A.; Hurst, S. Book Lovers, Technophiles, Pragmatists, and Printers: The social and demographic structure of user attitudes toward e-books. Coll. Res. Libr. 2012, 73, 420-429.

33. Merga, M.K. Access to Books in the Home and Adolescent Engagement in Recreational Book Reading: Considerations for Secondary School Educators. English in Education 2015. Available online: http://onlinelibrary.wiley.com/doi/10.1111/eie.12071/abstract (accessed on 29 July 2015).

34. Scholastic Inc. Kids and Family Reading Report, 5th ed.; Scholastic Inc.: New York, NY, USA, 2015.

35. Khan, K.S.; Kunz, R.; Kleijnen, J.; Antes, G. Five steps to conducting a systematic review. J. R. Soc. Med. 2003, 96, 118-121.

36. World Health Organisation (WHO). Adolescent Development. Available online: http://www. who.int/maternal_child_adolescent/topics/adolescence/dev/en/ (accessed on 6 June 2015).

37. Dierking, R. Using Nooks to hook reluctant readers. J. Adolesc. Adult Lit. 2015, 58, 407-416.

38. Dundar, H.; Akcayir, M. Tablet vs. paper: The effect on learners' reading performance. Int. Electron. J. Elem. Educ. 2012, 4, 441-450.

39. Jeong, H. A comparison of the influence of electronic books and paper books on reading comprehension, eye fatigue, and perception. Electron. Libr. 2010, 30, 390-408.

40. Tveit, A.K.; Mangen; A. A joker in the class: Teenage readers' attitudes and preferences to reading on different devices. Libr. Inf. Sci. Res. 2014, 36, 179-184.

41. Stoop, J.; Kreutzer, P.; Kircz, J. Reading and learning from screens versus print: A study in changing habits: Part 1-reading long information rich texts. New Libr. World 2013, 114, 284-300.

42. Staiger, J. How e-books are used. Ref. User Serv. Q. 2012, 51, 355-365.

43. Larson, L.C. Digital readers: The next chapter in e-book reading and response. Read. Teach. 2010, $64,15-22$.

44. Richardson, J.V., Jr.; Mahmood, K. eBook readers: User satisfaction and usability issues. Libr. Hi Tech 2011, 30, 170-185.

(C) 2015 by the author; licensee MDPI, Basel, Switzerland. This article is an open access article distributed under the terms and conditions of the Creative Commons Attribution license (http://creativecommons.org/licenses/by/4.0/). 